\title{
Skeletal morphology and material properties of a fragmenting gorgonian coral
}

\author{
M. L. Boller*, T. D. Swain, H. R. Lasker \\ Department of Biological Sciences, 103 Cooke Hall, University at Buffalo, Buffalo, New York 14260-1300, USA
}

\begin{abstract}
Among species in which fragmentation is an important mode of asexual reproduction, mechanisms that facilitate fragmentation should be advantageous. The Caribbean gorgonian Plexaura kuna readily fragments on reefs of the San Blas Islands, Panama, to form aggregations of genetically identical colonies. To understand the mechanics of fragmentation and the role of structural properties, the force required to break branches was measured on live colonies in the field, and morphology, flexibility, and strength of the axial skeleton were measured in laboratory experiments. Young's modulus, used as a measure of stiffness, was higher in P. kuna than in many other gorgonians and significantly varied among clones, ranging from 2.859 to $6.073 \mathrm{GN} \mathrm{m}^{-2}$. This level of variation indicates that drag should vary among clones due to differences in their flexibility. Of the morphological traits measured, coplanar constrictions influenced the force required to break a branch while anti-planar constrictions and branch anisotropy did not. The modulus of rupture, a measure of the strength of the branch, significantly varied among clones of $P$. kuna, ranging from 50.87 to $92.58 \mathrm{MN} \mathrm{m}^{-2}$. Using hydrodynamic theory we predict that the $55 \%$ variation in skeletal strength is sufficient to produce variation in fragmentation rate among clones. The stiffness of the skeleton of some colonies may prevent bending and shedding of drag resulting in failure due to the weakness of the skeleton. Clonal variation in flexibility and strength provides a mechanism through which selection may act to favor fragmentation and clonal growth.
\end{abstract}

KEY WORDS: Gorgonian · Biomechanics · Asexual $\cdot$ Reproduction $\cdot$ Clonal $\cdot$ Cnidaria $\cdot$ Coral

\section{INTRODUCTION}

The skeletons of sessile marine invertebrates, whether solid or hydrostatic, allow for the resistance of forces imposed by gravity and the motion of water. When these forces become too great an organism may fragment. While fragmentation causes mortality in many species, fragmentation among some taxa can prevent mortality of the whole colony by reducing colony size and subsequent drag imposed on the colony (e.g. Blanchette 1997). In addition, fragmentation serves as a mechanism of asexual reproduction in a variety of colonial animals including bryozoans

\footnotetext{
${ }^{*}$ Present address: Department of Biological Sciences, University of Rhode Island, 100 Flagg Road, Kingston, Rhode Island 02881, USA. E-mail: mbol1915@postoffice.uri.edu
}

(McKinney 1983), sponges (Wulff 1986, 1991), scleractinian corals (Highsmith 1982, Wallace 1985), and octocorals (Lasker 1984, 1990, Dahan \& Benayahu 1997). Through fragmentation a clone can increase in number of colonies without limit, and in doing so, survive the death of the original colony. Furthermore, the colonies that are generated when portions of an adult colony break off and establish a new colony are much larger than larvae and, therefore, avoid the high size dependent mortality associated with larval and juvenile life stages (Lasker 1990). These advantages may cause selection pressure favoring mechanisms that facilitate fragmentation.

The gorgonian coral Plexaura kuna (Cnidaria: Plexauridae) utilizes fragmentation to reproduce asexually (Lasker 1984). Asexual propagules are formed when the axial skeleton fails and whole branch groups become detached. While many small fragments do not 
survive, some fragments reattach to the substratum and form new colonies, resulting in the establishment of clones that can contain hundreds of colonies and extend over tens of meters of reef (Lasker \& Coffroth 1985, Lasker 1990, Coffroth \& Lasker 1998).

The fragmentation of Plexaura kuna branches, and gorgonians in general, is determined by the properties of the axial skeleton (Lewis \& Von Wallis 1991). Branches are constructed of a tissue matrix with embedded carbonate sclerites surrounding a proteinaceous axial skeleton that contains calcium carbonate inclusions (Goldberg 1976, Grillo et al. 1993). Calcium carbonate content of gorgonian axial skeleton is linearly correlated with stiffness (Jeyasuria \& Lewis 1987 , Esford \& Lewis 1990), and stiffness correlates to water movement regime (Jeyasuria \& Lewis 1987). Microstructure may also affect the material properties of the gorgonian skeleton, such as in bryozoans, where microstructure and mineral-organic composition are correlated with the resistance of the skeleton to failure in bending (Cheetham \& Thomsen 1981). Although the sclerite matrix has important effects on the mechanics of cnidarians without axial skeletons (Koehl 1982, 1996, West 1997), it has little effect on branch mechanics of gorgonians with axial skeletons (Lewis \& Von Wallis 1991).

Lasker (1984) compared the axial skeletons of Plexaura kuna and $P$. homomalla (a congener that does not readily fragment). The greater rate of fragmentation of $P$. kuna was attributed to the weakness of the axial skeleton and constrictions in the axes of some branches. Subsequent work based on multilocus DNA fingerprints (Coffroth \& Lasker 1998) has shown that the size of clones (i.e. the number of colonies that make up the clone) varies dramatically both within and between reefs. Lasker \& Coffroth (1995) also report that on many reefs female clones are larger than male clones. DNA fingerprinting data (Coffroth \& Lasker 1998, their unpubl. data) indicate that the colonies used in the Lasker (1984) study probably came from a single clone. Because the samples in Lasker's 1984 study were most likely genetically identical, we do not have an estimate of variance in the traits that facilitate fragmentation or of the effects of that variance on fragmentation. To better understand the fragmentation of $P$. kuna, we analyzed the bending and breaking of axial skeletons sampled from a range of clones.

The bending and breaking of a gorgonian branch can be described using static beam theory (Denny 1988). When a branch is bent the upper portion of the material is subjected to tensile deformation while the lower portion is compressed (Fig. 1). Between the tensile and compressive regions there is a neutral surface within the beam that is not deformed. Tensile and compressive deformations occur simultaneously within a bending beam, so simple stress/strain relationships do not apply. Additionally, the shape of a beam is important to its mechanics. The second moment of area $(I)$ describes the cross-sectional area and the distribution of that area relative to the application of force on a beam. It is calculated for an ellipse (because most Plexaura kuna skeletons were elliptical in cross-section) with the formula

$$
I=\frac{\pi b a^{3}}{4}
$$

where $a$ and $b$ are the diameters parallel and perpendicular to the application of force, respectively (Denny 1988). Elliptical beams with their major axis parallel to the application of force have a larger second moment of area.

Young's modulus $(E)$ describes the relationship between stress and strain for linearly elastic solids deformed in tension and compression (Wainwright et al. 1976, Alexander 1983). Static beam theory predicts the relationship between deflection, Young's modulus and the second moment of area as

$$
y=\frac{f L^{3}}{3 E I}
$$

where $y=$ deflection, $f=$ force, and $L=$ beam length (Denny 1988). When used in the analysis of a bending branch Young's modulus is inversely proportional to the flexibility of the material. Flexible skeletons, those

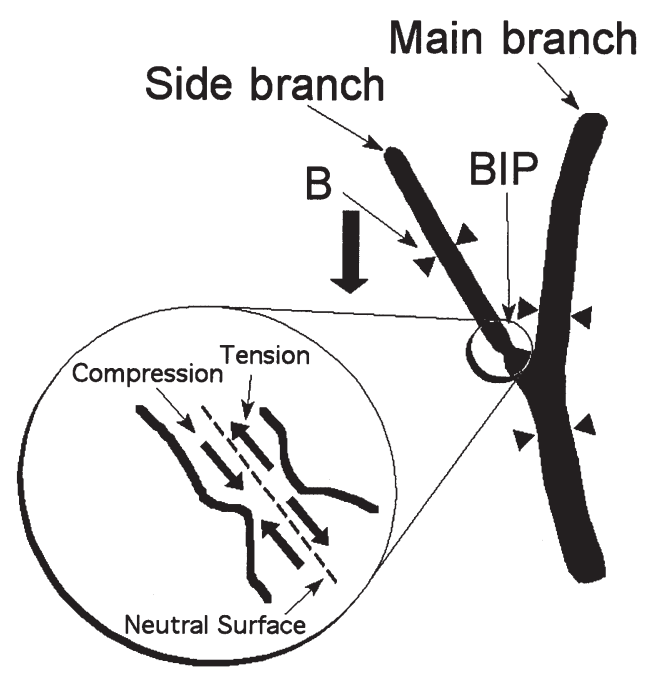

Fig. 1. Experimental set-up for the breaking of Plexaura kuna branches. Triangles represent the clamping points. Deflection (large arrow) was applied to the side branch and resisting force was measured with a load cell. Diameter measurements were taken for the branch (B) and the branch insertion point (BIP). The insert shows the internal stresses created by bending of the side branch. The modulus of rupture estimates the stress above the neutral surface that causes branch failure 
with low Young's modulus, bend when subjected to a force, like water flow. Bending reduces the crosssectional area projected into that flow and lessens the drag (Wainwright et al. 1976).

Lasker (1984) used the force required to fragment, a simple measurement that can be used to compare samples, to compare among Plexaura kuna colonies in the field. Another measure of strength in bending of the axial skeleton is the modulus of rupture $\left(M_{R}\right)$ : the maximum stress that a branch theoretically experiences in bending just before failure on the side deformed in tension (Singer 1962), in this case the portion of the branch above the neutral surface (Fig. 1). It can be calculated from the formula

$$
M_{\mathrm{R}}=\frac{M}{Z}
$$

where $M$ is the bending moment at failure (force at failure $\times$ moment arm length) and $Z$ is the second moment of area at the break point divided by the thickness of the sample from the neutral surface to the edge of the cross-section (assumed to be half the diameter normal to the neutral surface at the break point) (Singer 1962). This is not a property of the material but rather a theoretical stress that can be used to compare the ultimate strength of the structure. Thus, a branch with a large modulus of rupture will require more force to fragment than a morphologically identical branch with a small modulus of rupture. Using these measures, we report on a detailed analysis of the properties of $P$. kuna axial skeletons comparing among clones and between sexes and characterizing the roles of morphological and material properties.

\section{MATERIALS AND METHODS}

To assess variation in the potential for fragmentation among colonies we initially undertook a series of field measurements similar in design to Lasker's (1984) measurements of breaking force in Plexaura kuna. Field experiments were conducted in July 1995 in the San Blas Islands, Panama. Subsequent laboratory experiments that examined the fragmentation process in greater detail were conducted in 1999 on samples collected from the same area.

Field experiments. The field experiments conducted in 1995 examined the fragmentation properties of 25 Plexaura kuna colonies from 6 different reefs in the San Blas Point region. Coffroth \& Lasker (1998, their unpubl. data) had previously mapped the locations of clones on these reefs using DNA fingerprints to identify clonemates, and we assigned clone identities based on location on the different reefs. (Although fragments can be transported over 10 m [Lasker 1990],
Coffroth \& Lasker [1998] found few instances of intercalation of clones.) Colonies from a total of 19 different clones were used in the field experiments, but variation in breaking properties in these measurements was partitioned by colony, not by clone, because only a single colony was tested for most of the clones. Analyses also distinguished between male and female colonies (14 and 11 colonies respectively).

In these experiments a branch point on a colony was randomly selected, a cable tie was then attached at the branch tip and to a spring scale, and the branch was then pulled vertically down while the branch point was held in place (Lasker 1984). The deflection of the scale at the moment of failure was noted and breaking force calculated from the scale measurement $( \pm 0.2 \mathrm{~N}, 19.6 \mathrm{~N}$ maximum). The length of the branch and its diameter $5 \mathrm{~mm}$ above the insertion point (i.e. where the side and main branches met) were also measured $( \pm 0.01 \mathrm{~mm})$. Most of these measurements were conducted in situ on the intact colony. One set of measurements (8 colonies) were made on branches excised from the colony, returned (in seawater) to the field station and then immediately tested in identical manner in the water adjacent to the field station.

Laboratory experiments. Sections of Plexaura kuna colonies varying in size from 15 to $25 \mathrm{~cm}$ in maximum length were collected in the summer of 1996 from colonies at Korbiski, Niotupo, Tiantupo, and Point 24 reefs (see Coffroth \& Lasker 1998 for discussion of the reefs). Clone membership was determined as described above using the maps of Coffroth \& Lasker (1998, their unpubl. data). Clones of both sexes were sampled from Niotupo and Tiantupo reefs, while 1 male from Point 24 and 1 female from Korbiski were sampled (only 1 sex was available from these 2 reefs).

Tissue was stripped from the samples by immersing the branches in fresh water and then soaking them in salt water for approximately $24 \mathrm{~h}$. When the dead colony was soaked in seawater, the soft tissues of the gorgonian sloughed off the axis, leaving the axial skeleton and all of its branches intact. The skeletal samples were then frozen $\left(-20^{\circ} \mathrm{C}\right)$ for shipment and storage. In the lab, individual samples were thawed and rehydrated in artificial seawater (Instant Ocean, Aquarium Systems, Ohio) for $24 \mathrm{~h}$ prior to testing. Jeyasuria \& Lewis (1987) report that re-hydrated dry gorgonian skeletons regained material properties values not significantly different from fresh samples.

Morphological measurements were taken of each branch that was mechanically tested (Fig. 1). The branch cross-sections were elliptical; cross-sectional area and second moment of area were calculated from major and minor axes $( \pm 0.01 \mathrm{~mm})$. Branch major and minor axes did not always occur in the same plane, so measurements, and the constrictions revealed by those 
measurements, were designated as either coplanar or anti-planar. The coplanar diameter was within the plane of the side and main branch. That is, if the branch were laid flat on the table, the plane would parallel to the table. The anti-planar diameter was perpendicular to the plane. The 2 diameters were also used to determine branch anisotropy, i.e. differences in the orientation of the major and minor axes with respect to the application of force. To quantify the presence and magnitude of constrictions, the diameter at visible constrictions (or $\sim 1 \mathrm{~mm}$ from the branch insertion point if no constriction was present) was compared to diameters taken $5 \mathrm{~mm}$ distal from the point of insertion of the branch. We refer to these as branch insertion point (BIP) and branch (B) diameters, respectively. Branches with a constriction had BIP diameters that were less than the $\mathrm{B}$ diameters $(\mathrm{BIP}<\mathrm{B})$. A constriction index was defined as BIP/B. Branches were divided into classes based on the constriction index where any branch with an index less than 1.0 was classified as constricted. We calculated a constriction index for each branch for both the coplanar and anti-planar diameters as well as by total branch area.

Each colony sample contained 10 to 40 branch points and all branch points that connected branches longer than $5 \mathrm{~cm}$ were mechanically tested. These branch points were separated by cutting the samples into sections, each composed of a main branch and a single side branch. Mechanical data were collected using a Mechanochemical Materials Tester (Columbia Laboratories, Buffalo, NY) modified to deflect the branches as cantilever beams. Samples were tested while submerged in artificial seawater to prevent desiccation.

The fragmentation of colonies in the field is complex due to the turbulent motion of the water and branches are probably subjected to a wide variety of force vectors. Ideally, up, down, left and right deflection of the branch would have been done in order to cover a greater range of possible deflection in the field. We deflected the side branch straight down, i.e. parallel to the main branch (Fig. 1), because this application of force should be similar to some of the natural forces experienced by the distal branches of a colony in the horizontal motion of wave surge or during turbulent flow and is easily duplicated, allowing us to compare many samples. The main branch was held with clamps at 2 points, each $2.5 \mathrm{~mm}$ from the point of insertion of the side branch to prevent torsion of the branch and to isolate movement to the side branch (Fig. 1). The side branch was clamped $5 \mathrm{~mm}$ from the point of insertion and was deflected at a constant rate $\left(\sim 8.46 \mathrm{~mm} \mathrm{~min}^{-1}\right)$ while a load cell (Sensotech, Columbus, Ohio) measured the resisting force exerted by the branch $( \pm 0.015 \mathrm{~N})$. Measurements of time and resisting force were recorded on a chart recorder until failure of the branch. Some branches $(41 \%$ of the trials) either slipped from the clamps or failed at one of the points where the branch was clamped. These cases, which can be attributed to the experimental apparatus, were not considered further. Branches that slipped during experiments usually showed signs of damage from the clamps and were not reused. After failure of the branch, the distance from the application of force (Fig. 1) to the break point and the diameters at the break point (measurements needed for the calculation of the modulus of rupture) were measured for all samples except those from Korbiski and Point 24. Branches from these 2 reefs were used for force and flexibility analyses only. Chart recordings of the experiments yielded plots of force versus time. Time was converted to deflection based on the constant speed at which the branch was deflected during the experiment. Young's modulus $(E)$ was determined using the linear regression of $f \times L^{3}$ against $3 \times y \times I$ derived from the formula for small deflections of a beam (Eq. 2). The modulus of rupture was calculated using Eq. (3). Because this formula incorporates the morphology at the break point (even if the failure occurred directly next to the constriction), we believe that it is independent of any effects of constriction and use it as a measure of the strength of the branch.

\section{RESULTS}

\section{Field experiments}

Results of the experiments conducted in the San Blas Islands were similar to those obtained in previous work (Lasker 1984), but exhibited greater levels of variance, reflecting the greater number of colonies, clones, and sites involved in the analyses. Branches in the field failed over a range of 0.1 to $7.8 \mathrm{~N}$, but, as is evident in Fig. 2, the majority of branches failed at forces less

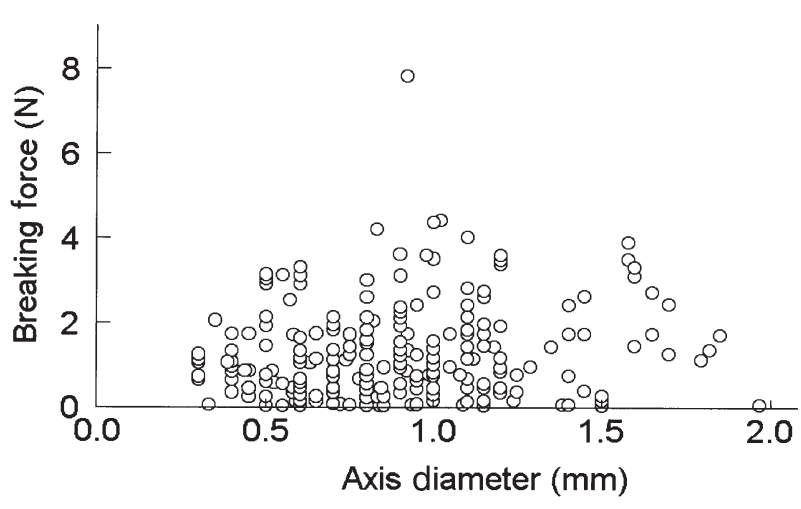

Fig. 2. Force at failure vs branch cross-sectional area for data obtained in the field 
than $4.0 \mathrm{~N}$ (mean $=1.3 \mathrm{~N}, \mathrm{SE}=0.4)$. Detailed analysis of the data reveal a complex set of relationships affecting branch failure. Field and laboratory data were analyzed for differences among colonies and sexes using nested analysis of variance (MANOVA analysis using SPSS 9.0). Even after transformation, field data were heteroscedastic and complementary analyses were conducted on rank transformed data. There were significant differences among colonies but not between sexes in both axis diameter (nested ANOVA: between sexes: $F=2.28$, df $=1,24, \mathrm{p}=0.14$; among colonies within sexes: $F=4.33$, df $=24,220, \mathrm{p}<0.001$ ) and branch length (nested ANOVA: between sexes: $F=0.498$, df $=1,22, p=0.49$; among clones within sexes: $F=2.18$, df $=22,202, p=0.003$ ). Breaking force was related to axis diameter among colonies (ANCOVA: between sexes: $F=0.215$, df $=1,24, \mathrm{p}=0.64$; among colonies within sexes: $F=2.01$, df $=24,219$, $\mathrm{p}=0.005)$, but as is evident in Fig. 2, the relationship was weak, describing only $11 \%$ of the variance in breaking force.

\section{Laboratory experiments}

Branch cross-sectional area and the coplanar constriction index were compared between sexes and among clones within sexes (Table 1). Values were log transformed to homogenize the variances among classes. Neither area (nested ANOVA: between sexes: $F=0.54, \mathrm{df}=1,184, \mathrm{p}=0.46$; among clones within sexes: $F=1.63$, df $=7,184, \mathrm{p}=0.12$ ) nor constriction index (nested ANOVA: between sexes: $F=1.11$, $\mathrm{df}=1,184, \mathrm{p}=0.29$; among clones within sexes: $F=0.76$, $\mathrm{df}=7,184, \mathrm{p}=0.62$ ) varied between sexes or among clones within sexes. Of the 142 branches from which mechanical data were collected, $46 \%$ had coplanar constrictions and $85 \%$ had anti-planar constrictions.

All branches were deflected until failure or until the force became too great for the clamps to hold the sample. As previously noted, experimental artifacts occurred in $41 \%$ of the 347 trials. Of the remaining 205 trials, failure occurred near the point of insertion of the side branch in $97 \%$ of the cases. In $3 \%$ of those trials, failure occurred on the main axis and were not included in the analyses because the mechanics of failure were not interpretable. Variation in the success rates of our experimental procedure might have indicated that a clone had an axial skeleton that was too strong to be held by our clamps. No variation was observed in the frequency of successful trials between sexes or among clones within sexes (log linear analysis, SPSS: $\chi^{2}=11.67, \mathrm{df}=17, \mathrm{p}=0.82$ ), indicating our procedure did not bias the results.

Samples failed in the following manner: As the branch was deflected down, discoloration was often observed in the crook near the branch insertion point. The branch usually broke 0.5 to $2.0 \mathrm{~mm}$ from the point of insertion and $64 \%$ of those samples that broke on the side branch failed at the constriction. The break was accompanied by an audible crack, and the failure characteristically extended $1 / 2$ to $3 / 4$ the way through the axis. The force required for branch failure increased with branch cross-sectional area (Figs. 3 \& 4). Branches failed over a range of 0.37 to $22.31 \mathrm{~N}$ (mean $=2.6 \mathrm{~N}, \mathrm{SE}=0.24$ ). Branches that had coplanar constrictions (Fig. 3B) failed at lower forces than non-constricted branches (Fig. 3A) of similar proportions (ANCOVA: $F=10.29$, df $=1,2$,

Table 1. Branch cross-sectional area $\left(\mathrm{mm}^{2}\right)$, constriction index, Young's modulus $\left(\mathrm{GN} \mathrm{m}^{-2}\right)$ and modulus of rupture $\left(\mathrm{MN} \mathrm{m}^{-2}\right)$ of laboratory analyzed Plexaura kuna samples by sex and clone within sex. The prefix in the clone identifier refers to the reef of origin; $\mathrm{K}=$ Korbiski, $\mathrm{N}=$ Niotupo, $\mathrm{Pt}=$ Point 24, and $\mathrm{Ti}=$ Tiantupo. Clones were independently named by a letter code; thus $\mathrm{K}-\mathrm{C}$ and $\mathrm{N}-\mathrm{C}$ are different clones. Modulus of rupture values were not calculated for clones K-C and Pt-A due to a lack of necessary data

\begin{tabular}{|c|c|c|c|c|c|c|c|c|c|c|c|c|}
\hline \multirow[b]{2}{*}{ Clone } & \multicolumn{3}{|c|}{ Branch area } & \multicolumn{3}{|c|}{ Constriction index } & \multicolumn{3}{|c|}{ Young's modulus } & \multicolumn{3}{|c|}{ Modulus of rupture } \\
\hline & $\mathrm{n}$ & Mean & $\mathrm{SD}$ & $\mathrm{n}$ & Mean & $\mathrm{SD}$ & $\mathrm{n}$ & Mean & $\mathrm{SD}$ & $\mathrm{n}$ & Mean & $\mathrm{SD}$ \\
\hline All samples & 193 & 4.20 & 2.91 & 193 & 1.05 & 0.17 & 193 & 4.11 & 2.95 & 140 & 75.02 & 3.29 \\
\hline Females & 77 & 4.89 & 3.07 & 77 & 1.01 & 0.17 & 77 & 3.73 & 2.27 & 77 & 67.80 & 2.61 \\
\hline $\mathrm{K}-\mathrm{C}$ & 21 & 5.83 & 2.58 & 21 & 1.04 & 0.20 & 21 & 3.27 & 2.13 & & & \\
\hline $\mathrm{N}-\mathrm{C}$ & 20 & 4.15 & 2.78 & 20 & 1.02 & 0.23 & 20 & 4.87 & 3.19 & 20 & 73.30 & 2.67 \\
\hline $\mathrm{N}-\mathrm{H}$ & 16 & 3.75 & 1.22 & 16 & 0.98 & 0.09 & 16 & 3.11 & 0.88 & 16 & 50.87 & 1.28 \\
\hline Ti-B & 20 & 5.56 & 4.32 & 20 & 0.10 & 0.13 & 20 & 3.58 & 1.74 & 19 & 76.26 & 2.81 \\
\hline Males & 116 & 3.73 & 2.71 & 116 & 1.08 & 0.17 & 116 & 4.36 & 3.31 & 116 & 79.69 & 3.59 \\
\hline N-B & 16 & 4.42 & 3.60 & 16 & 1.09 & 0.18 & 16 & 2.86 & 1.44 & 16 & 68.04 & 3.13 \\
\hline N-D & 21 & 3.58 & 2.17 & 21 & 1.13 & 0.16 & 21 & 3.79 & 2.94 & 21 & 80.14 & 5.17 \\
\hline $\mathrm{N}-\mathrm{G}$ & 23 & 3.53 & 3.07 & 23 & 1.10 & 0.18 & 23 & 3.07 & 1.54 & 23 & 73.36 & 2.36 \\
\hline Pt-A & 30 & 3.71 & 2.33 & 30 & 1.07 & 0.19 & 30 & 6.07 & 4.82 & & & \\
\hline Ti-A & 26 & 3.64 & 2.70 & 26 & 1.04 & 0.13 & 26 & 4.91 & 2.50 & 25 & 92.58 & 2.96 \\
\hline
\end{tabular}




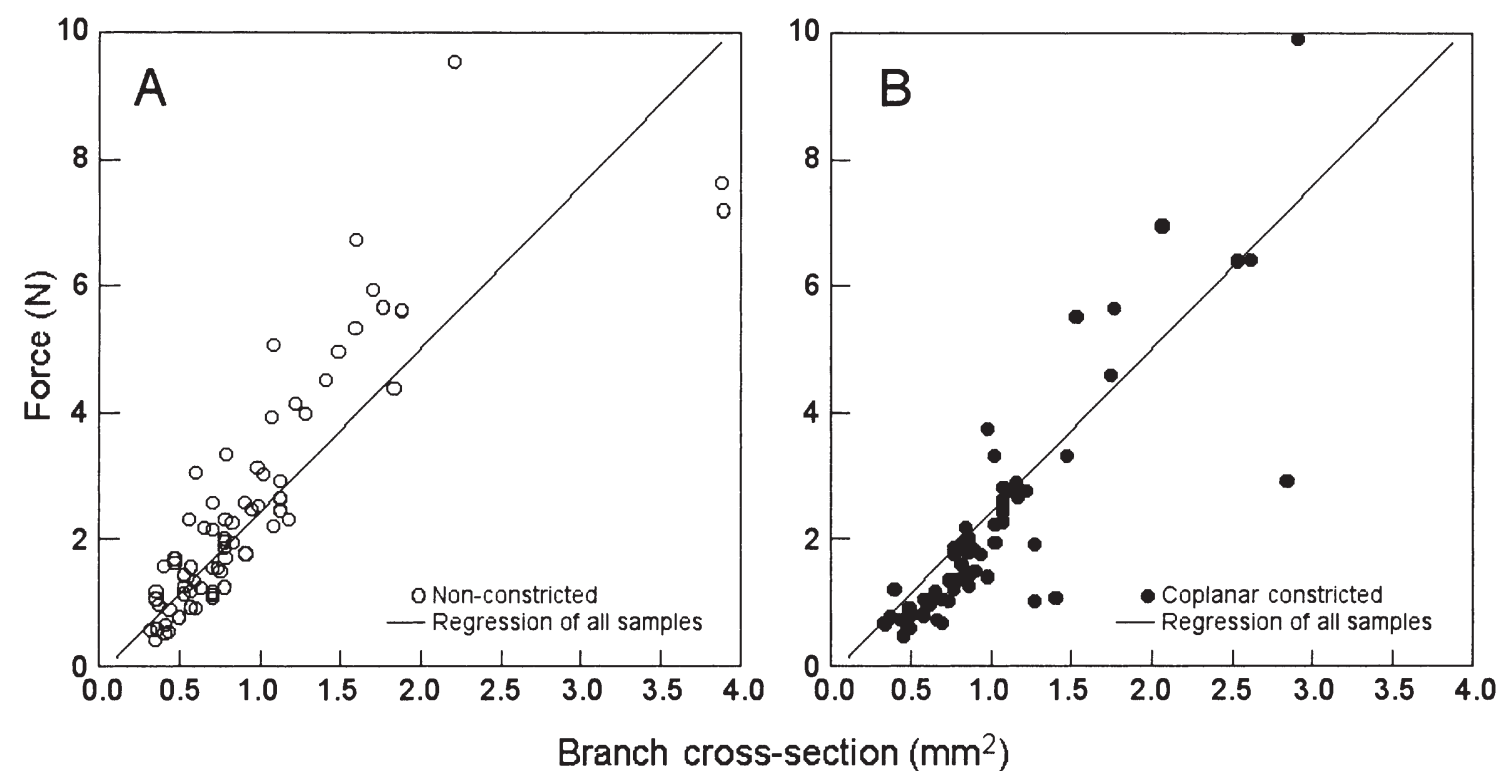

Fig. 3. Force at failure vs branch cross-sectional area for coplanar non-constricted (A) and constricted (B) branches tested in the laboratory. Coplanar constriction significantly reduced the force needed for failure of the branch. The line is the regression of all branches, constricted and non-constricted

$\mathrm{p}=0.002$ ). Anti-planar constriction (Fig. 4B) did not decrease the force required for failure when compared to non-constricted branches (Fig. 4A; ANCOVA: $F=0.567$, $\mathrm{df}=1,2, \mathrm{p}=0.453$ ). Anisotropy of branches without constrictions (Fig. 5) had no effect on the force at failure (ANCOVA: $F=0.643$, df $=1,2, \mathrm{p}=0.428$ ).

Young's modulus varied from 3.07 to $6.07 \mathrm{GN} \mathrm{m}^{-2}$ and the modulus of rupture varied from 50.87 to
92.58 $\mathrm{MNm}^{-2}$ among clones (Table 1). There was no significant variation in either Young's modulus or modulus of rupture between sexes (nested ANOVA: $F=0.96$, df $=1,7, \mathrm{p}>0.05 ; F=6.20, \mathrm{df}=1,5, \mathrm{p}>0.25$, respectively), but variation was found among clones within sexes for both variables $(F=3.32$, df $=7,184$, $\mathrm{p}=0.002 ; F=4.10, \mathrm{df}=5,133, \mathrm{p}=0.002$, respectively).
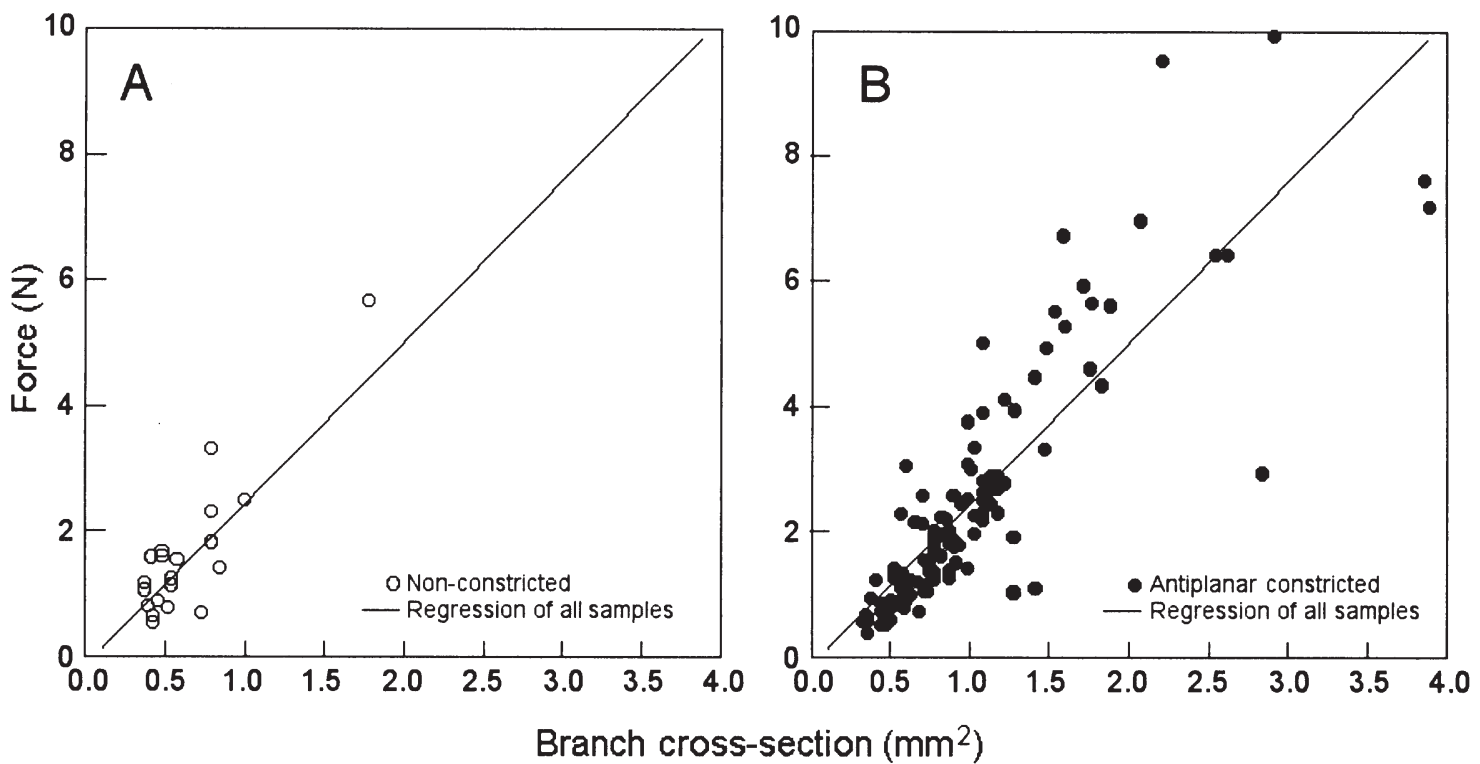

Fig. 4. Force at failure vs branch cross-sectional area for anti-planar non-constricted (A) and constricted (B) branches tested in the laboratory. Anti-planar constriction did not significantly reduce the force needed for failure of the branch. The line is the regression of all branches, constricted and non-constricted 


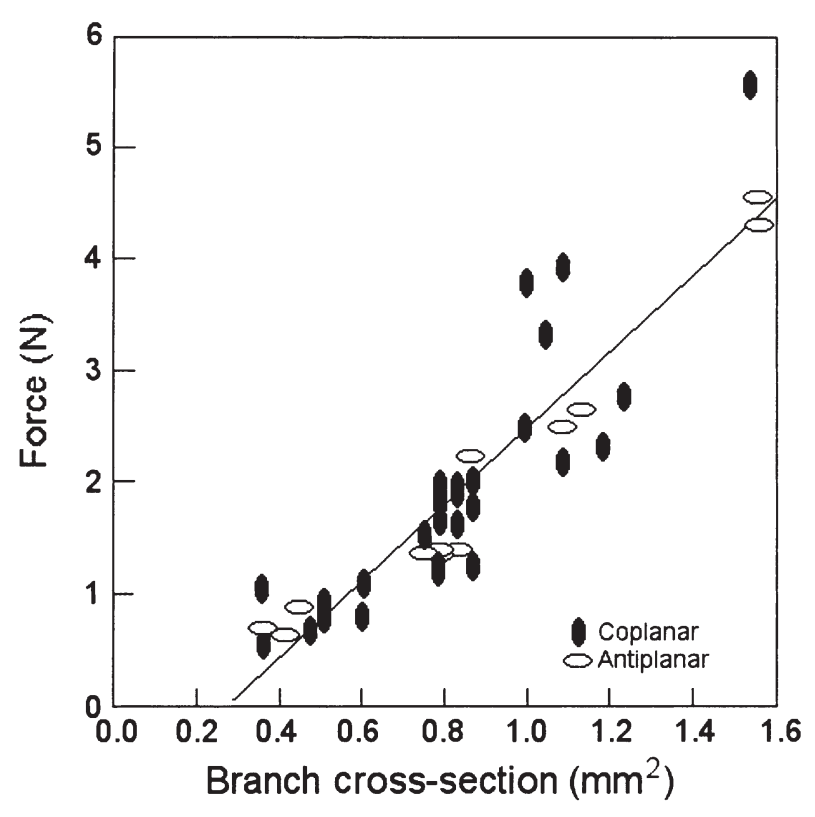

Fig. 5. Force at failure vs branch cross-sectional area for nonconstricted branches showing anisotropy tested in the laboratory. Coplanar orientated branches have greater diameter for the coplanar measurement than the anti-planar. Anti-planar orientated branches have greater diameter for the anti-planar measurement than the coplanar. No significant difference was seen between the 2 types of branch

\section{DISCUSSION}

\section{Flexibility of the Plexaura kuna axis}

Skeletal stiffness, measured as Young's modulus, correlates with the environment in which a gorgonian lives (Jeyasuria \& Lewis 1987, Esford \& Lewis 1990). Species in shallow, moderate wave surge environments have the least stiff skeletons; higher energy environments have moderately stiff skeletons; species from deeper environments with little or no surge have the stiffest skeletons (Jeyasuria \& Lewis 1987). Stiffness of the skeleton is important for the support of the animal off the substratum and for the best positioning of the polyps for biological activity (e.g. feeding, exposing zoozathellae to light) (Jeyasuria \& Lewis 1987). Flexibility allows the colony to orientate branches parallel to the water flow. Reorientation reduces the projected surface area of the colony, its resistance to water flow, and reduces the drag on the colony (Wainwright et al. 1976, Koehl 1984, Jeyasuria \& Lewis 1987, Denny et al. 1998).

Flexibility and reorientation also affect other aspects of the ecology of gorgonians. Failure of the holdfast due to the stress created by drag of the entire colony is the primary source of mortality among many gorgonians (e.g. Birkeland 1974) so reduction of drag can be beneficial. Flexibility in very high flow may also affect resource capture. Polyps are deformed in high flows reducing their feeding efficiency (Lasker 1981). When the skeleton is extremely flexible, such as that of Pseudopterogorgia americana, the swaying action of a branch can effectively slow the ambient flow around polyps reducing deformation and giving them more time to catch food particles (Wainwright et al. 1976, Sponaugle \& LaBarbera 1991). However, extremely long flexible branches may be susceptible to fragmentation due to the excessive momentum, as in kelps (Denny et al. 1998, Koehl 1998).

The flexibility of the Plexaura kuna axial skeleton material, measured as Young's modulus (4.110 $\mathrm{GN} \mathrm{m}^{-2}$ ), is among the higher published values for gorgonian skeletons (Table 2). Young's modulus for gorgonian

Table 2. Young's modulus and modulus of rupture data for gorgonian axial skeleton and other biological materials. Young's modulus is given in $\mathrm{GN} \mathrm{m}^{-2}$ and the modulus of rupture in $\mathrm{MN} \mathrm{m}^{-2}$

\begin{tabular}{|c|c|c|}
\hline & $\begin{array}{l}\text { Young's } \\
\text { modulus }\end{array}$ & $\begin{array}{l}\text { Modulus } \\
\text { of rupture }\end{array}$ \\
\hline \multicolumn{3}{|l|}{ Gorgonians } \\
\hline Ellisella barbadensis ${ }^{\mathrm{a}}$ & 9.03 & \\
\hline Lophorgogia cardinalis ${ }^{a}$ & 5.04 & \\
\hline Plexaurella grise $^{\mathrm{a}}$ & 4.49 & \\
\hline Plexaura kuna & 4.11 & 75.02 \\
\hline Leptogorgia virgulata $^{\mathrm{a}}$ & 3.55 & \\
\hline Pseudopterogorgia bipinnata ${ }^{\mathrm{a}}$ & 3.31 & \\
\hline Plexaura homomalla ${ }^{\mathrm{f}}$ & 1.84 & \\
\hline Pterogorgia citrina $^{\mathrm{a}}$ & 1.55 & \\
\hline Gorgonia ventalina $^{\mathrm{a}}$ & 1.32 & \\
\hline Plexaura flexuosa ${ }^{\mathrm{a}}$ & 0.99 & \\
\hline Eunicea calyculata $^{\mathrm{a}}$ & 0.72 & \\
\hline Swifta exserta ${ }^{a}$ & 0.70 & \\
\hline Muriceopsis flavida $^{\mathrm{a}}$ & 0.70 & \\
\hline Eunicea clavigera $^{\mathrm{a}}$ & 0.63 & \\
\hline Pseudoplexaura crucis ${ }^{\mathrm{a}}$ & 0.58 & \\
\hline \multicolumn{3}{|l|}{ Others } \\
\hline Acorapora palmatac & 21.5 & \\
\hline Siderastrea radians ${ }^{\mathrm{e}}$ & 15.1 & \\
\hline Montastrea annularis ${ }^{\mathrm{e}}$ & 10.6 & \\
\hline 'Hard coral' & & 27 \\
\hline Bracebridgia subsulcata (Bryozoan) & d 65.11 & 50.48 \\
\hline Cystisella saccata (Bryozoan) ${ }^{\mathrm{d}}$ & 42.46 & 24.13 \\
\hline Membranipora savartii (Bryozoan) ${ }^{\mathrm{b}}$ & & 78.00 \\
\hline Echinus plate ${ }^{\mathrm{b}}$ & 23 & 9.7 \\
\hline Conus prometheus shell ${ }^{\mathrm{b}}$ & 67.7 & 125.0 \\
\hline Stombus gigas shell ${ }^{\mathrm{b}}$ & 40.7 & 73.2 \\
\hline Nautilus pompilius shell ${ }^{\mathrm{b}}$ & 44.5 & 206.4 \\
\hline Pinctada shell ${ }^{\mathrm{C}}$ & 48.4 & 172.7 \\
\hline Hippopus hippopus shell ${ }^{\mathrm{C}}$ & 53.3 & 37.5 \\
\hline Homarus ssp. claw ${ }^{\mathrm{c}}$ & 4.2 & 7.4 \\
\hline Cow femurc & 18 & 270 \\
\hline \multicolumn{3}{|c|}{$\begin{array}{l}\text { a Jeyasuria \& Lewis (1987), }{ }^{\mathrm{b}} \text { Currey \& Taylor (1974), } \\
{ }^{\mathrm{c}} \text { Wainwright et al. (1976), }{ }^{\mathrm{d}} \text { Cheetham \& Thomsen (1981), } \\
{ }^{\mathrm{e} C h a m b e r l a i n}(1978),{ }^{\mathrm{f}} \text { Esford \& Lewis (1990) }\end{array}$} \\
\hline
\end{tabular}


skeletal material ranges from 0.580 to $9.032 \mathrm{GN} \mathrm{m}^{-2}$, Pseudoplexaura cruces and Ellisella barbadensis, respectively (Jeyasuria \& Lewis 1987). Among P. kuna clones, Young's modulus values ranged from 2.86 to 6.07 $\mathrm{GN} \mathrm{m}^{-2}$, which is comparable to the stiffer gorgonian axis material of Pseudopterogorgia bipinnata, Leptogorgia virgulata, Plexaurella grisea, and Lophorgogia cardinalis. P. kuna is less flexible than its congener $P$. homomalla $\left(E=1.84 \mathrm{GN} \mathrm{m}^{-2}\right.$; Esford \& Lewis 1990). Although the reefs of San Blas where $P$. kuna is found are generally subject to low-energy levels, periodic high-energy squalls occur and cause fragmentation in P. kuna (Lasker 1984, Coffroth \& Lasker 1998). The $P$. kuna axis does not have as much flexibility to bend and shed the drag during storms as other species in similar environments do. Instead it fragments, thus reducing the colony size and drag. This self-pruning is also seen in the intertidal alga Fucus gardneri, where wave action causes loss of tissue and prevents holdfast failure (Blanchette 1997). In addition to the decreased drag, fragmentation allows the species to flourish because of the ability of fragments to reattach to the substrate. However, Coffroth \& Lasker (1998) speculate that $P$. kuna is limited from very high-energy environments where fragmentation rates would be too great, causing colony death.

The range of values from the 1999 experiments also suggests that the variation in flexibility may influence variation in fragmentation rate. The most flexible clone $\left(\mathrm{N}-\mathrm{B} ; 2.859 \mathrm{GN} \mathrm{m}^{-2}\right.$ )was twice as flexible as the least (Pt-A; $6.073 \mathrm{GN} \mathrm{m}^{-2}$ ). If identical branches from each of these clones were subjected to the same drag, branches from the N-B colonies would flex approximately twice as far as those from Pt-A colonies. Drag on an object is calculated from

$$
\operatorname{Drag}=\frac{1}{2} \rho u^{2} A C_{\mathrm{d}}
$$

where $\rho$ is the density of seawater $\left(1024 \mathrm{~kg} \mathrm{~m}^{-2}\right), u$ is velocity, $A$ is the area projected in the flow, and $C_{\mathrm{d}}$ is the drag coefficient (Denny 1988). Because the drag on a flexible object is related to the shape of the object and the shape can be altered by flow, it is hard to predict precisely the extent to which flexibility will influence drag (Vogel 1994). At the very least, area projected into the flow will decrease more in more flexible colonies, thereby reducing drag.

Additionally, Vogel (1994) defines a measure of reconfiguration of an object subject to drag as the Evalue (not to be confused with Young's modulus). An E- value near -2 indicates that drag is independent of velocity and thus flexibility and reconfiguration would have little effect on drag. Pseudopterogorgia americana and $P$. acerosa have E-values of -1.59 and -1.73 respectively (Sponaugle \& LaBarbera 1991). A sclerac- tinian coral, Acropora reticulata, has a positive E-value of 0.26 (Vogel 1994). While many factors influence the E-value, stiffness in the Plexaura kuna axis most likely results in higher (less negative) E-values and consequently higher drag. The relationship between Young's modulus and the E-value has yet to be explored in biological systems.

\section{Axial morphology}

The clearest finding of the 1995 experiment was that colonies/clones differ from each other in virtually all traits. Morphologically they varied in the diameter and length of branches and that translated into differences in the forces required for fragmentation. The 1999 data indicate those differences have a strong genetic (i.e. clonal) component.

In both the 1995 and 1999 experiments, the force required to break a branch was influenced by branch diameter. This pattern was best seen in the later experiments (Figs. 3-5). One source of variation in the branch diameter/force relationship in Figs. 3 \& 4 was the axial constriction present in some branches. A constriction in the axial skeleton behaves like a simple notch in a beam under stress. When loaded in tension, a notch in a uniform solid concentrates the force trajectories (Wainwright et al. 1976). A constriction effectively reduces the cross-sectional area through which the force trajectories can travel, thus concentrating the stress in the branch. When the stress becomes greater than the strength of the material, failure occurs. The deeper and sharper the constriction, the greater the concentration of force trajectories, so branches with constrictions should be less strong than similar branches without constrictions. Branches that had coplanar constrictions failed at lower forces than non-constricted branches, demonstrating that the effective crosssectional area of the branch is lowered due to the constriction (Fig. 3). Anti-planar constrictions did not lower breaking force despite the difference in crosssectional area because the constriction reduced the width in the neutral plane (Fig. 4), which has a smaller effect on the second moment of area than a similar coplanar constriction (Eq. 1).

The shape of the branch should also affect the force required to cause failure. An anisotropic beam, made of a uniform material, is stronger if the long axis is parallel to the bending force. This relationship is even seen in bryozoans (Cheetham \& Thomsen 1981), where the material is clearly non-uniform. We expected gorgonian axes with greater coplanar than anti-planar diameter to be stronger than circular axes of equivalent cross-sectional area but the effects of branch anisotropy were not evident in our data. 
Branch anisotropy and constrictions should have an effect on breaking force because they both change the second moment of area of the branch (Singer 1962). Because the calculation of the second moment of area is proportional to the square of the coplanar diameter (Eq. 1) changes in that diameter have a greater effect on the strength of the branch. Changes in the antiplanar diameter are linearly proportional to the second moment of area, so anti-planar constrictions should have less of an effect. The lack of any effect by antiplanar constrictions demonstrated that this aspect of the branch's mechanics is consistent with static beam theory.

Branch anisotropy should also change the strength of the branch but did not. This discrepancy may be due to the microstructure of the Plexaura kuna axis, the helical structure observed on the branch surface (pers. obs.) or the slight angle of molecular orientation (Wainwright et al. 1976). The effects of forces on a branch may be altered if protein fibers transfer the force trajectories around the central axis of the branch. While this phenomenon would affect constrictions as well, it is apparent that the effects of coplanar constrictions outweigh any microstructure effects.

The constrictions also guide the location at which fragmentation takes place. Among naturally occurring fragments collected in San Blas, 82\% had constrictions at the point of failure (Lasker 1984). Among the constricted branches used in our laboratory experiments, failure occurred at the constriction $64 \%$ of the time. Size affects fragment survival, and fragment survival and reattachment is greatest among intermediate size fragments (Lasker 1990). The concentration of force trajectories by constrictions, in combination with the drag created by larger branch sections, guides the skeleton to break at branch points that will produce fragments large enough to establish new colonies.

\section{Axis strength}

The forces required to fragment the Plexaura kuna axis in the field and laboratory were very similar, averaging 1.3 and $2.6 \mathrm{~N}$, respectively, and in most cases branches failed at less than $6 \mathrm{~N}$. These forces, or greater, are likely to occur on reefs during storms. While water velocities have never been measured in San Blas during a storm, water velocities approaching $0.5 \mathrm{~m} \mathrm{~s}^{-1}$ have been measured during relatively calm conditions on reefs similar to those in San Blas (Helmuth \& Sebens 1992, Sebens \& Done 1992, Sebens 1997). Wave action during storms can generate very high flows on reefs, and Woodley et al. (1981) calculated wave generated horizontal velocities of $5.4 \mathrm{~m} \mathrm{~s}^{-1}$ at depths of $15 \mathrm{~m}$ during Hurricane Allen. The reefs in
San Blas never experience such large waves, but they are subject to severe squalls during the rainy season. $P$. kuna is commonly found at 1 to $4 \mathrm{~m}$ depth in San Blas and it is likely that water velocities in shallow water fall in the 1 to $10 \mathrm{~m} \mathrm{~s}^{-1}$ range during squalls. Turbulent flow velocities may be much higher.

Plexaura kuna drag coefficients have not been measured but the minimum drag coefficient for reconfigured Pseudopterogorgia americana is $\sim 0.2$ (taken from figure; Sponaugle \& LaBarbera 1991), and we suspect that values for $P$. kuna are much higher. The drag on a hypothetical gorgonian branch section with an average branch diameter of $2.5 \mathrm{~mm}$ (Lasker et al. 1996) and total branch length of $66 \mathrm{~cm}$ (estimated from a Ti-B colony fragment) would exceed the average force required for failure $(2.6 \mathrm{~N})$ at $4 \mathrm{~m} \mathrm{~s}^{-1}$ flow with drag coefficients greater than 0.2 (Fig. 6).

Comparison of the modulus of rupture of Plexaura kuna to other biological materials is difficult due to a scarcity of published data for similar tissues (Table 2). The modulus of rupture for $P$. kuna skeletons had an average value of $75.02 \mathrm{MN} \mathrm{m}^{-2}$. This value is much higher than the published value of $27 \mathrm{MN} \mathrm{m}^{-2}$ for 'hard coral' (Wainwright et al. 1976). Adeoniform bryozoan skeletons have moduli of rupture (ranging from 24 to $78 \mathrm{MN} \mathrm{m}^{-2}$ ) in a similar range of values to $P$. kuna (Cheetham \& Thomsen 1981; data here for rewetted and fresh samples only). Some mollusk shells, such as that of the gastropod Strombus gigas $\left(73.2 \mathrm{MN} \mathrm{m}^{-2}\right.$ ) have similar strengths, while others, such as Turbo marmoratus and Hippopus hippopus, are stronger $\left(266 \mathrm{MN} \mathrm{m}^{-2}\right.$ ) or weaker (37.5 $\mathrm{MN} \mathrm{m}^{-2}$ ) respectively (Currey \& Taylor 1974). Unfortunately, no modulus of rupture data are available for other gorgonians, but previous work by Lasker (1984) suggests that modulus

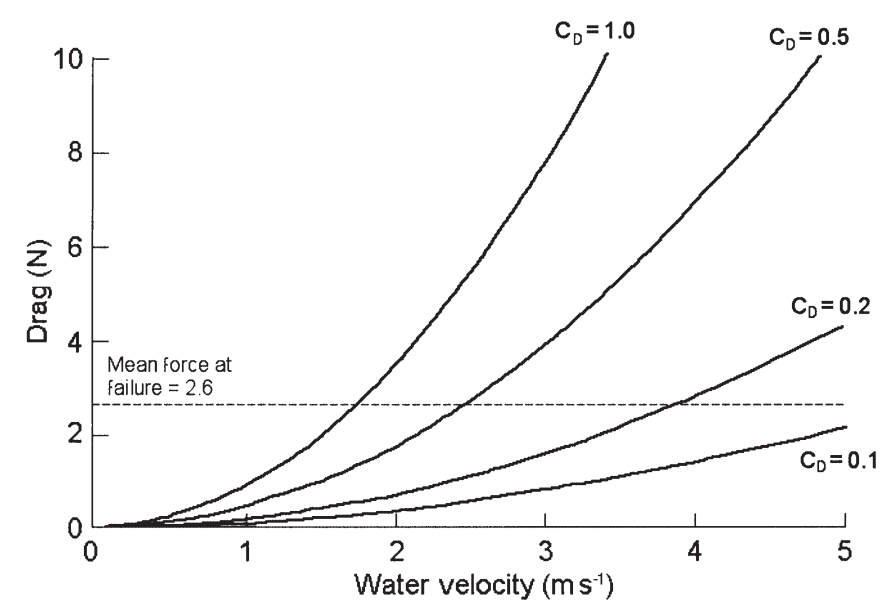

Fig. 6. Drag created by a model Plexaura kuna at varying water velocities and drag coefficients. Dashed line represents the mean force required to fragment branches in the laboratory 
of rupture values measured in $P$. homomalla would be higher than those of $P$. kuna.

Breaking force exhibited significant variation at the colony level in the field measurements. This suggests that some colonies were more likely to fragment than others but did not demonstrate that skeletal strength was constant within a genotype or that strength was a trait that might be acted upon by selection. Clone, i.e. genotype, specific differences in fragmenting were examined in the laboratory experiments. Modulus of rupture values among clones indicated that some clones are more likely to fragment than others due to the weakness of their axial skeleton. Clone N-H (the weakest) had $55 \%$ of the skeletal strength of clone Ti-A (the strongest). If 2 theoretical branches, from $\mathrm{N}-\mathrm{H}$ and Ti-A, were of equal size, shape, and area, the difference in strength would be directly proportional to differences in the maximum force the skeleton could withstand. The N-H branch will fragment when drag is $55 \%$ of that exerted on the theoretical Ti-A branch. Because drag is proportional to the square of fluid velocity (Eq. 4) and our branches have identical drag coefficients because of the equal size, shape, and area, the theoretical $\mathrm{N}-\mathrm{H}$ skeleton would fail at a water velocity $30 \%$ lower than that necessary to fragment the theoretical Ti-A branch. This suggests that realistic levels of water flow variation can produce variation in fragmentation rate. Any flow ranging from the minimum flow required to fragment the weak clone to the minimum required to fragment the stronger clone will result in the weaker clone producing fragments.

Variation in the mechanical properties of Plexaura kuna colonies should affect fragmentation rates in nature, which may then influence the relative size of clones. However, clone size reflects the combined effects of fragmentation, fragment survival, survival, and age of the clone as well the hydrodynamic regime on the reef. Among the 9 clones from 4 reefs for which we gathered data, neither Young's modulus nor the modulus of rupture was correlated with clone size estimates derived from Coffroth \& Lasker (1998, their unpubl. data). A better measure of the effects of mechanical properties on the size of clones would be the rate of fragment formation, which we would expect to more closely correlate with the colonies' mechanical properties.

\section{CONCLUSIONS}

Fragmentation occurs in a variety of coral reef taxa (see Highsmith 1982, Lasker 1984, Wulff 1986, 1991), and traits that facilitate fragmentation have been documented in a variety of branching organisms. Bioerosion of Acropora cevicornis by boring sponges creates weak points in the skeleton and reduces the force needed to fragment colonies (Tunnicliffe 1981, 1982). Hydrodynamically unfavorable growth patterns in Millepora complanata result in fragmentation and asexual reproduction (Lewis 1991). The erect growth forms and structural weakness of branching sponges lead to the establishment of clonal structure (Wulff 1986, 1991). This ability to fragment was detrimental in an extreme storm when weak clones of 1 erect sponge had disproportionately high mortality after Hurricane Joan (Wulff 1995). Similarly, Coffroth \& Lasker (1998) suggest that the features that promote fragmentation of Plexaura kuna in habitats with intermittent disturbance prevent the establishment of extensive clones in habitats subject to very high levels of disturbance.

Among Plexaura kuna the flexibility of the branch, the morphology of the skeleton, and the strength of the axis material all influence the fragmentation of colonies. The higher stiffness of the $P$. kuna axis when compared to other gorgonians, may prevent some colonies from bending in a flow to shed drag, thereby exposing the axis to higher forces and causing fragmentation at a greater rate than for a more flexible skeleton. Coplanar axial constrictions decreased the force necessary to fragment a branch while anti-planar constrictions did not. Variation among clones in the strength of the axis suggested that this property influences the ability of a clone to fragment. Theoretically, the weakest clone will fragment and establish colonies in water flows that are up to $30 \%$ lower than the flow needed to fragment the strongest clone.

Fragmentation of colonies can be viewed as an unfortunate event in the history of a colony; as a feature shaped by selection to allow a colony to shed drag and thereby survive periods of high flow; or as a feature shaped by selection to facilitate the spread of a clone across a reef. If, as we would argue, selection plays a role in the occurrence of fragmentation among Plexaura kuna colonies, then there must be heritable variation in the phenotypic traits that control fragmentation. The presence of clonal variation in Young's modulus and the modulus of rupture provide an opportunity for selection to operate on fragmentation and suggests that fragmentation among these colonies can be interpreted as a 'strategy'. The 3 alternatives listed above are not mutually exclusive and discerning their relative roles in explaining the variance of fragmentation among $P$. kuna colonies requires further examination.

Acknowledgements. Our thanks to Mary Alice Coffroth, Tamar Goulet, Scott Santos and Alan Verde, who assisted in fieldwork and added comments. We thank Lydia Bright, Emily Carrington, Carla Gutiérrez Rodríguez, Juan Sanchez, and Tonya Snell for their comments and James Stamos for his assistance with the figures. We greatly appreciate all of the assistance given to us by Dr Robert Bier, Robert Forsberg, and the members of the Biomaterials Lab of the University at Buf- 
falo, School of Dental Medicine. Our work in San Blas was made possible by the efforts of the staff of the Smithsonian Tropical Research Institute, and our continued thanks is given to Reynaldo Tapia, the San Blas Station Manager. We thank the people of the Kuna Nation and the Republic of Panama for permission to work in San Blas and are grateful for the support of the National Science Foundation (to H.R.L.), the Howard Hughes Medical Institute Undergraduate Biology Initiative (to T.D.S.), and the Smithsonian Tropical Research Institute.

\section{LITERATURE CITED}

Alexander RM (1983) Animal mechanics. Blackwell Scientific Publishers, Oxford

Birkeland C (1974) The effect of wave action on the population dynamics of Gorgonia ventalina Linnaeus. Stud Trop Oceanogr 12:115-126

Blanchette CA (1997) Size and survival of intertidal plants in response to wave action: a case study with Fucus gardneri. Ecology 78:1563-1578

Chamberlain JA (1978) Mechanical properties of coral skeleton: compressive strength and its adaptive significance. Paleobiology 4:419-435

Cheetham AH, Thomsen E (1981) Functional morphology of arborescent animals: strength and design of cheilostome bryozoan skeletons. Paleobiology 7:355-383

Coffroth MA, Lasker HR (1998) Population structure of a clonal gorgonian coral: the interplay between clonal reproduction and disturbance. Evolution 52:379-393

Currey JD, Taylor JD (1974) The mechanics of behaviour of some molluscan hard tissues. J Zool 173:395-406

Dahan M, Benayahu Y (1997) Clonal propagation by the azooxanthellate octocoral Dendronephthya hemprichi. Coral Reefs 16:5-12

Denny MW (1988) Biology and mechanics of the wave swept environment. Princeton Univ Press, Princeton, NJ

Denny MW, Gaylord B, Helmuth B, Daniel T (1998) The menace of momentum: Dynamic forces on flexible organisms. Limnol Oceanogr 43:955-968

Esford LE, Lewis JC (1990) Stiffness of Caribbean gorgonians (Coelenterata, Octocorallia) and $\mathrm{Ca} / \mathrm{Mg}$ content of their axes. Mar Ecol Prog Ser 67:189-200

Goldberg WM (1976) Comparative study of the chemistry and structure of gorgonian and antipatharian coral skeletons. Mar Biol 49:253-267

Grillo MC, Goldberg WM, Allemand D (1993) Skeleton and sclerite formation in the precious red coral Corallium rubrum. Mar Biol 117:119-128

Helmuth B, Sebens KP (1992) The influence of colony morphology and orientation to flow on particle capture by the coral Agaricia agaricites (Linnaeus). J Exp Mar Biol Ecol $165: 1-28$

Highsmith RC (1982) Reproduction by fragmentation in corals. Mar Ecol Prog Ser 7:207-226

Jeyasuria P, Lewis JC (1987) Mechanical properties of the axial skeleton in gorgonians. Coral Reefs 5:213-219

Koehl MAR (1982) Mechanical design of spicule-reinforced connective tissue: stiffness. J Exp Biol 98:239-267

Koehl MAR (1984) How do benthic organisms withstand moving water? Am Zool 24:57-70

Koehl MAR (1996) Mechanical design of sclerite-reinforced skeletons. Am Zool 36:55A

Koehl MAR (1998) Biomechanics: the quirks of jerks. Nature 396:621-623

Editorial responsibility: Ronald Karlson (Contributing Editor), Delaware, Newark, USA
Lasker HR (1981) A comparison of the particulate feeding abilities of three gorgonian soft corals. Mar Ecol Prog Ser 5:61-67

Lasker HR (1984) Asexual reproduction, fragmentation, and skeletal morphology of a plexaurid gorgonian. Mar Ecol Prog Ser 19:261-268

Lasker HR (1990) Clonal propagation and population dynamics of a gorgonian coral. Ecology 71:1578-1589

Lasker HR, Coffroth MA (1985) Vegetative reproduction, clonal spread, and histocompatibility in a Caribbean gorgonian. Proc 5th Int Coral Reef Cong, Tahiti 4:331-336

Lasker HR, Coffroth MA (1995) Fragmentation in a gorgonian coral: Phenotypic variation and the opportunity for selection. Am Zool 35(5):137A

Lasker HR, Kim K, Coffroth MA (1996) Reproductive and genetic variation among Caribbean gorgonians: the differentiation of Plexaura kuna, new species. Bull Mar Sci 58: $277-288$

Lewis JB (1991) Testing the coral fragment size-dependent survivorship hypothesis for the calcareous hydrozoan Millepora complanata. Mar Ecol Prog Ser 70:101-104

Lewis JS, Von Wallis E (1991) The function of surface sclerites in gorgonians (Coelenterata, Octocorallia). Biol Bull 181: $275-288$

McKinney FK (1983) Asexual colony multiplication by fragmentation: an important mode of genet longevity in the Carboniferous bryozoan Archimedes. Paleobiology 9: $35-43$

Sebens KP (1997) Adaptive responses to water flow: morphology, energetics, and distribution of reef corals. Proc 8th Int Coral Reef Symp 2:1057-1058

Sebens KP, Done TJ (1992) Water flow, growth form and distribution of Scleractinian corals: Davies reef (GBR), Australia. Proc 7th Int Coral Reef Symp 1:557-568

Singer FL (1962) Strength of materials. Harper and Brothers, New York

Sponaugle S, LaBarbera M (1991) Drag-induced deformation: a functional feeding strategy in two species of gorgonians. J Exp Mar Biol Ecol 148:121-134

Tunnicliffe V (1981) Breakage and propagation of the stony coral Acoropora cervicornis. Proc Natl Acad Sci USA 78: $2427-2431$

Tunnicliffe V (1982) The effects of wave-induced flow on a reef coral. J Exp Mar Biol Ecol 64:1-10

Vogel S (1994) Life in moving fluids. Princeton Univ Press, Princeton, NJ

Wainwright SA, Biggs WD, Currey JD, Gosline JM (1976) Mechanical design in organisms. John Wiley and Sons, New York

Wallace CC (1985) Reproduction, recruitment and fragmentation in nine sympatric species of the coral genus Acropora. Mar Biol 88:217-233

West JM (1997) Plasticity in the sclerites of a gorgonian coral: Tests of water motion, light level, and damage cues. Biol Bull 192(2):279-289

Woodley JD and 19 others (1981) Hurricane Allen's impact on Jamaican coral reefs. Science 214:749-755

Wulff JL (1986) Variation in clone structure of fragmenting coral reef sponges. Biol J Linn Soc 27:311-330

Wulff JL (1991) Asexual fragmentation, genotype success, and population dynamics of erect branching sponges. J Exp Mar Biol Ecol 149:277-247

Wulff JL (1995) Effects of a hurricane on survival and orientation of large erect coral reef sponges. Coral Reefs 14: $55-61$

Submitted: April 12, 2000; Accepted: June 18, 2001

Proofs received from author(s): February 5, 2002 